F. Reprod. Fert. (1969) 20, 407-412

\title{
THE POSITION AND SPACING OF IMPLANTATION SITES IN THE UTERUS OF THE RAT DURING EARLY PREGNANCY
}

\author{
J. E. O'GRADY AND P. J. HEALD \\ Department of Biochemistry, University of Strathclyde, \\ George Street, Glasgow, C.1
}

(Received 29th October 1968)

\begin{abstract}
Summary. A study has been made of the distribution and spacing of implantation sites in the uterus of the rat at the 5th day of pregnancy. It has been shown that, whereas the implantation sites along the horns are distributed in an entirely random manner, the distances between the sites are significantly non-random. These results are similar to those previously described for the rabbit and the mouse, and rule out the possibility of predicting a site of incipient implantation in the uterus of the rat.
\end{abstract}

\section{INTRODUCTION}

During preliminary investigations using the Psychoyos 'blue reaction' (Psychoyos, 1965) as a means of visualizing the sites of blastocyst implantation in the uterus of the rat on Day 5 of pregnancy, it was noted that, when several uterine horns were placed adjacent to each other for storage at $-18^{\circ} \mathrm{C}$, the sites appeared to occur at similar positions in each uterus. Since a major study in these laboratories relates to biochemical changes occurring before and during implantation, it was apparent that, if the implantation sites occupied regular and predictable areas of the uterus, changes at the site could be studied before the blastocyst arrived and implantation commenced.

Mossman (1937) stated "It is a common observation that mammalian embryos of species having more than one young to a litter have a fairly definite behaviour as to the position in the uterus at which they implant or attach", but a search of the literature produced no evidence in support of this view and it has been disproved in the mouse (McLaren \& Michie, 1959). No data existed for the rat and, accordingly, an examination of the distribution and spacing of blastocyst implantation sites in rat uterus was undertaken.

\section{MATERIALS AND METHODS}

The rats used were adult, virgin females of a Holtzman strain of SpragueDawley, and were maintained in windowless rooms at $75^{\circ} \mathrm{F}$ on a lighting schedule from 06.00 hours to 20.00 hours G.M.T. Animals were caged three females to one male, and the morning on which spermatozoa were found in the vaginal smears was designated Day 1 . At noon on Day 6, half the rats were 
lightly anaesthetized with ether and $2.0 \mathrm{mI}$ of a solution of Niagara Blue 2B $(2.0 \mathrm{~g} / 100 \mathrm{ml} 0.9 \% \mathrm{w} / \mathrm{v}$ saline $)$ was injected into the tail vein or femoral vein. Ten minutes later the animals, still under anaesthesia, were killed and the uteri rapidly dissected, trimmed free from fat and pinned out with mapping pins on filterpaper moistened with saline and laid on a cork board. The pins were inserted at the junction of the two horns and at the extremities just below the ovaries. Each horn was thus placed under a slight tension. The lengths of the horns, the distance of the implantation sites from the junction of the horns and the size of the implantation sites were measured with callipers and recorded in $\mathrm{mm}$. All distances were then calculated as percentages of the total length of any one uterine horn to enable comparisons to be made between horns of differing length. Care was taken to distinguish between the right and left horns.

\section{RESULTS}

Numbers and size of implantation sites

A total of twenty-three rats was examined, containing 330 implantation sites, 160 in the right horn and 170 in the left horn. The most commonly found number of sites was between six and nine, but in any one rat there were differences in actual numbers between the right and left horn. The most commonly found length of the sites was $2 \cdot 0$ to $3.0 \mathrm{~mm}$.

\section{Frequency of distribution}

To determine the likelihood of blastocysts implanting at predetermined sites in the uteri, the frequency of distribution was calculated by dividing the total uterine lengths (expressed as a percentage) into arbitrary sections of $3 \%$ and determining the number of times the centre of an implantation site was found within any one section. These frequencies were summed for each $3 \%$ section and the cumulative totals plotted against the truncate range, 0 to $99 \%$.

For any given number of sites, a perfectly random positioning would be expected to fall on a line whose slope equalled the number of sites divided by the total distance over which sites were found. Any significant deviation from randomness would show as a series of slipwise deviations from the theoretical random line.

The results of such plots for the distribution of sites in both the right and left horns are presented in Text-fig. 1 and Text-fig. 2, and show that the distribution of sites is that expected from a perfectly random distribution with the exception of an area 3 to $4 \%$ from the ovarian end of the horns where no implantation sites were observed.

\section{Evenness of spacing of sites}

The evenness, or otherwise, of the spacing of the implantation sites was tested in a manner similar to that described by Böving (1954) for the rabbit uterus. Thus, the distances between the implantation sites (expressed as a percentage of the total length of the uterine horn) were summed to give a mean \pm S.D. for each horn, and parallel calculations were made on an identical number of random numbers from 00 to 99 (Fisher \& Yates, 1963) set down in 


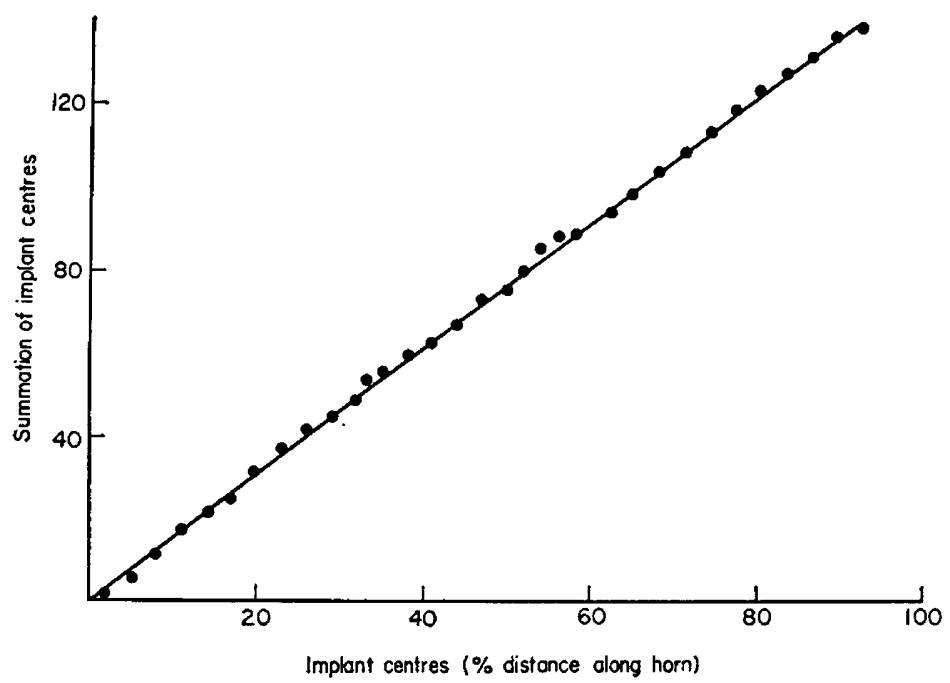

TEXT-FIG. 1. A plot of the distribution of implantation sites in the right horns of uteri of rats $5 \frac{1}{2}$ days after mating. The calculated random distribution is given by the solid line and the distribution found is given by the filled circles. For procedures involved, see the Materials and Methods section. The $100 \%$ mark is the ovarian end.

sequence. The standard deviations were then divided by the means to yield the coefficients of variation. The coefficients were summed for each group of uteri (grouped according to the number of implantation sites contained) and the mean \pm S.D.M. of each was compared with a similar mean \pm S.D.M. derived

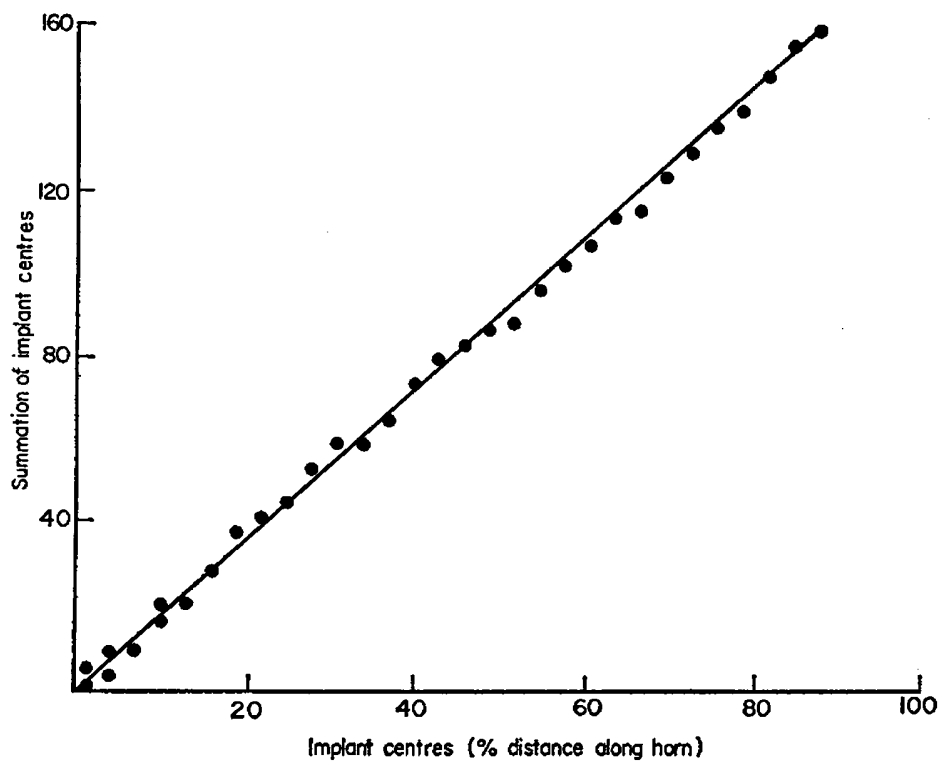

TEXT-FIG. 2. A plot of the distribution of implantation sites in the left horns of uteri of rats $5 \frac{1}{2}$ days after mating. The calculated random distribution is given by the solid line and the distribution formed is given by the filled circles. The $100 \%$ mark is the ovarian end. 
TABLE 1

COMPARISONS OF EVENNESS OF DISTRIBUTION OF UTERINE IMPLANTATION WITH RANDOM DISTRIBUTIONS

\begin{tabular}{|c|c|c|c|c|c|c|c|}
\hline $\begin{array}{l}\text { No. of } \\
\text { sites }\end{array}$ & $\begin{array}{l}\text { No. of } \\
\text { uteri }\end{array}$ & $\begin{array}{c}\text { Mean } \\
\text { distance } \\
\text { between } \\
\text { sites }\end{array}$ & $\begin{array}{l}\text { Degrees of } \\
\text { freedom }\end{array}$ & $\begin{array}{c}\text { Coeff. variation } \\
\text { of uteri } \\
\pm S . D . M .\end{array}$ & $\begin{array}{c}\text { Coeff. variation } \\
\text { of random } \\
\text { numbers } \\
\pm S . D . M .\end{array}$ & $\mathbf{t}$ & $\mathbf{P}$ \\
\hline $\begin{array}{r}5 \\
6 \\
7 \\
8 \\
9 \\
10\end{array}$ & $\begin{array}{l}4 \\
8 \\
9 \\
8 \\
5 \\
4\end{array}$ & $\begin{array}{r}12 \cdot 72 \\
9 \cdot 51 \\
9 \cdot 04 \\
7 \cdot 85 \\
6 \cdot 08 \\
6.05\end{array}$ & $\begin{array}{r}38 \\
94 \\
124 \\
126 \\
88 \\
78\end{array}$ & $\begin{array}{l}0.286 \pm 0.18 \\
0.364 \pm 0.048 \\
0.249 \pm 0.034 \\
0.393 \pm 0.064 \\
0.382 \pm 0.078 \\
0.262 \pm 0.184\end{array}$ & $\begin{array}{l}1 \cdot 14 \pm 0.83 \\
0.98 \pm 0.80 \\
1 \cdot 12 \pm 0.45 \\
1 \cdot 16 \pm 0.53 \\
1 \cdot 14 \pm 0.68 \\
1 \cdot 11 \pm 0.87\end{array}$ & $\begin{array}{l}6 \cdot 373 \\
2 \cdot 52 \\
7 \cdot 45 \\
2 \cdot 37 \\
2 \cdot 39 \\
3 \cdot 41\end{array}$ & $\begin{array}{l}P<0.01 \\
0.01>P>0.02 \\
P<0.01 \\
0.01>P>0.02 \\
0.01>P>0.02 \\
P<0.01\end{array}$ \\
\hline
\end{tabular}

from equal sets of random numbers. Comparison was made, using the Student $t$ test and the results are presented in Table 1. It was clear that there was a significant difference between the distances separating the implantation sites and the distance expected for a perfectly random spacing.

It will also be noted from Text-fig. 3 that the mean $\%$ of the uterine distance between each implantation site became smaller as the number of implantation sites increases.

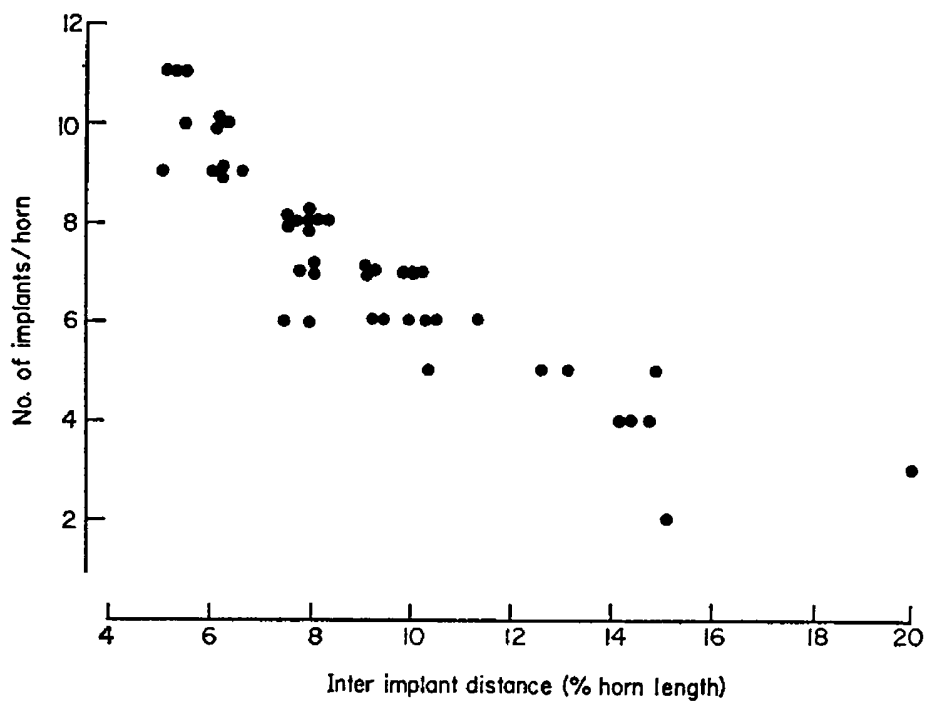

TEXT-FIG. 3. The distances between implantation sites in both right and left horns of rats $5 \frac{1}{2}$ days after mating shown in relation to the number of sites in each horn. Distances are expressed as a percentage of the horn length.

\section{DISCUSSION}

The finding of a completely random distribution of implantation sites in the uterus of the rat establishes that the premise which gave rise to the work, namely that it might be possible to predict the site of incipient implantation, is not valid. Until the actual implantation site can be visualized, it is at present 
not possible to undertake biochemical investigation of a section of the uterus in the expectation that some metabolic aspect may differ, as regards preparation for implantation, from that in any other section.

The finding that the spacing between the implantation sites is significantly non-random is similar to that previously shown by Böving (1954) in the rabbit. However, in Böving's series, the data from all the rabbits were pooled, irrespective of the number of sites/horn. In the present series, the greater number of rats used permitted a separation of uteri into groups according to the number of sites in each. Even so, the relationship of an evenness of spacing significantly different from random was found in all instances whether uteri contained four or ten sites. The situation here is analogous to that which would occur if a series of evenly-spaced pegs fixed to a strip of wood were laid a number of times in a completely unselected manner on a fixed length of pipe. It can be seen that in a series of such placings, it is possible that the pegs could at some time touch any point of the pipe and the distribution of such placings along the pipe would thus be random. Nevertheless, the distance between the pegs would always be even. The blastocysts are clearly implanting at any point, and therefore the position of these points are random, but once an initial selection has been made, it is as though the blastocysts space themselves out in a roughly even manner. The reasons why this type of distribution occurs in the uterus can only be conjectural.

Accompanying the increase in number of implantation sites was a decrease in the mean distance between the sites. These changes in spacing would appear to argue against the hypothesis (Mossman, 1937) that spacing is brought about by serial implantation starting at the ovarian end of the uterine horn and the development of local refractory zones, for it is difficult to see how a decrease in the number of blastocysts implanting would be accompanied by an increase in the distance between the sites. More reasonably, the data presented here is in accord with the suggestions of Böving (1954) for the rabbit, and McLaren \& Michie (1959) for the mouse, that the position of the blastocyst in the uterus is determined by muscular contraction which operates in such a way as to strive for the maximum separation of the blastocysts, both with respect to each other and to the end of the uterus.

Further and more detailed discussions of the significance of this type of result have been given by Böving (1954) and McLaren \& Michie (1959) and the present study, by its nature, cannot add further to the interpretation. It does, however, firmly establish a pattern of distribution for blastocysts in the rat, which is similar to those previously available only for the rabbit and the mouse.

\section{ACKNOWLEDGMENT}

We wish to thank the M.R.C. for a Grant in support of the work and Dr Anne McLaren for helpful discussion at its commencement.

\section{REFERENCES}

Böving, B. C. (1954) In: The mammalian fetus: physiological aspects of development. Cold Spring Harb. Symp. quant. Biol. 19, 9. 
Fisher, R. A. \& YATEs, F. (1963) Statistical tables, 6th edn. Oliver \& Boyd, Edinburgh.

McLaren, A. \& Michie, D. (1959) The spacing of implantations in the mouse uterus. Mem. Soc. Endocr. 6, 65.

Mossman, H. W. (1937) Comparative morphogenesis of the fetal membranes and accessory uterine structures. Contr. Embryol. 26, 129.

Pschoyos, A. (1965) Contrôle de la nidation chez les mammifères. Archs Anat. microsc. morph. exp. 54, 85. 